\title{
Isolation and Characterization of Ciprofloxacin Resistant Salmonella from the Wastes of Hospital Patients
}

\author{
AMMAChowdhury ${ }^{1}$, M Nural Anwar* \\ Department of Microbiology, ${ }^{1}$ Department of Genetic Engineering and Biotechnology, University of Chittagong, Chittagong 4331, Bangladesh.
}

(Received 10 January 2010; Accepted 15 May, 2010)

\begin{abstract}
In this investigation, 12 ciprofloxacin resistant Salmonella were isolated from medical waste samples. Identified Salmonella isolates were then subjected to sensitivity analysis against five antibiotics. All the ciprofloxacin resistant Salmonella isolates were resistant to ampicillin, amoxicillin, and penicillin and were considered multidrug resistant. Growth of four ciprofloxacin resistant Salmonella from four medical samples at various concentrations (50 to $500 \mathrm{mg} / \mathrm{ml}$ ) was measured. Three of four Salmonella isolates from medical samples showed growth even against $500 \mathrm{mg} / \mathrm{ml}$ of ciprofloxacin. The occurrence of these highly resistant isolates in medical samples indicated the high percentage of undigested ciprofloxacin in medical waste sample. Agarose gel electrophoresis of these 12 isolates showed no plasmid DNA band indicating that observed resistance might be chromosomal gene mediated.
\end{abstract}

Key words: Hospital wastes, Salmonella, Ciprofloxacin, Multidrug resistant

\section{Introduction}

In nature, wide spread occurrence of Salmonella spp. linked with the intensive husbandry practice used in meat, fish, and shrimp processing industries and inedible raw materials into animal feed have favored the continued prominence of this bacterial pathogen in global food chain. They can be easily present in earthen ponds and other unprotected water bodies that are continuously exposed to environmental contamination.

Salmonella may cause three types of infection namely enteric fever (typhoid and paratyphoid fever), enterocolitis (gastroenteritis) and septicemia in human ${ }^{1}$. Typhoid fever is one of the major causes of morbidity and mortality in developing countries $^{2}$. In the last two decades, the worldwide emergence of multi-resistant Salmonellae has led to the application fluoroquinolones and broad-spectrum cephalosporins against Salmonella infections ${ }^{3}$. However, nalidixic acid-resistant strains (MIC, $\geq 32 \mathrm{mg} /$ liter) exhibiting reduced susceptibility to ciprofloxacin (MICs, 0.125 to $1 \mathrm{mg} /$ liter) have emerged and become endemic in South and South-East Asia ${ }^{4-6}$. Such strains have also been reported from other parts of the world ${ }^{7-8}$. Consequently, there is treatment failure with ciprofloxacin in patients infected with this organisms ${ }^{7-9}$. Enteric fever isolates that are either multidrug resistant or with reduced susceptibility to ciprofloxacin reported from expatriate workers of South Asian origin from Kuwait $^{9-10}$. Although there are reports from India ${ }^{11-12}$,
Bangladesh ${ }^{13-14}$ and $\mathrm{Nepal}^{15}$ of Salmonella enterica serovar Typhi strains fully resistant to ciprofloxacin.

Resistance may occur in Salmonella through the liberal administration of antibiotic in hospital or in other treatment centre. Hospitals serve as centers for the emergence and transmission of drug-resistant microorganisms. Hospitals also provide a fertile environment for antibiotic-resistant germs as close contact among sick patients and extensive use of antibiotics select for resistant bacteria. Ciprofloxacin is being used in Chittagong Medical College Hospital as a fourth generation antibiotic for treating various diseases in several wards. The excessive use of this antibiotic contributes in resistance development in flora like Salmonella in the environment after it is excreted with feces or urine. Medical College Hospital can contribute in developing antibiotic resistant bacteria in the environment. The present experiment was undertaken to find out how and in what proportion the hospital is distributing the resistance phenomenon among the bacteria Salmonella against the broad spectrum antibiotic ciprofloxacin.

\section{Materials and methods \\ Sample collection}

Sample was collected from Chittagong Medical College (CMC) hospital. In various ward of the hospital, the hospitalized patients released their discharges (stool, urine, etc.) in the toilet. From toilet these wastes passes through a pipe into a septic tank.

*Corresponding author

Dr. Md. Nural Anwar, Professor, Department of Microbiology, University of Chittagong, Chittagong-4331, Bangladesh.

Tel (office): 031- 726311-14.Ext- 4464 ;Cell-01716430243, Email anwarmn51@yahoo.com 
Chowdhury et al.

Samples were collected according to the wastes position and named as followed. Sample 1 was collected from entrance position of the septic tank. It was the position in which patient discharges (stool, urine, etc) were deposited before entered into the septic tank. Sample 2 was collected from outlet position of the pipe by which septic tank wastes are released into the hospital drain. Sample 3 was collected from the position where hospital drain mixed with the out side drain. Sample 4 was collected from the drain which was situated in front of the hospital. There was no direct connection of hospital back side drain with this drain, but this drain was connected with the hospital out side drain.

\section{Isolation and identification}

All the samples were separately pre-enriched in buffer peptone water containing ciprofloxacin $50 \mu \mathrm{g}$ per ml. After 24 hours incubation, the cultures were enriched in selective broth at $37^{\circ} \mathrm{C}$ for 24 hours. After selective enrichment, a loop-full of culture from each sample was streaked onto Bismuth sulphate Agar (BSA) plates containing ciprofloxacin. After overnight incubation, 20 colonies were selected on BSA plates and named as according to sample name, example S1CipR2 which means ciprofloxacin resistant colony from sample 1 . The selected colonies were isolated as pure culture and presumptive test (Triple Sugar Iron Test) of the pure cultures were done. Isolates showing positive results in presumptive test were further studied by morphological and biochemical test including Gram staining, Urease test (UT), Lactose fermentation test (LFT), Mannitol Fermentation test (MFT), Oxidase test (OT), Citrate test (CT), Motility test (MT), Methyl red test (MRT), Voges Proskauer (V.P) test.

\section{Antibiotic bioassay}

Antibiotic sensitivity test of the ciprofloxacin resistant Salmonella were done by disc diffusion method ${ }^{16}$ on Mueller Hinton Agar medium with disks containing chloramphenicol ( $30 \mu \mathrm{g})$, amoxicillin $(10 \mu \mathrm{g})$, ampicillin $(10 \mu \mathrm{g})$, tetracycline $(30 \mu \mathrm{g})$ and ciprofloxacin (50 $\mu \mathrm{g})$,

Growth measurement at different concentrations of antibiotics For this experiment 4 isolates were selected from 4 samples. The selected isolates were S1cipR2, S2cipR7, S3cipR16 and S4cipR20. Nutrient broth was prepared, dispensed in to test tubes and sterilized by autoclaving. Then different concentration of ciprofloxacin ranging from 50, 100, 200, 300, 400 and $500 \mathrm{ig} / \mathrm{ml}$ of broth were added into the test tubes. Then the test tubes were inoculated with isolates of samples 1, 2, 3 and 4 and were incubated in a rotatory shaker at $37^{\circ} \mathrm{C}$ for overnight. After incubation growth were measured at $600 \mathrm{~nm}$ (absorbance) by spectrophotometer and recorded.

\section{Extraction of plasmid}

To determine, whether the antibiotic resistance was plasmidmediated or not, these isolates were subjected to plasmid DNA extraction and agarose gel electrophoresis according to the procedure of Sambrook et al. ${ }^{17}$

\section{Results and Discussion}

Ciprofloxacin resistant Salmonella spp were isolated from CMC waste samples using pre-enrichment technique. According to the presumptive test result, 12 isolates were selected from all samples for staining and identification test. Gram staining of all the isolates showed that the isolates were Gram negative and rod shaped. The isolates were identified by 9 bio-chemical tests (Table 1). According to the colony character, presumptive test and biochemical test results, the isolates were found to belong to Salmonella spp (Table- 1).

Table 1. Identification of Salmonella isolates from medical wastes

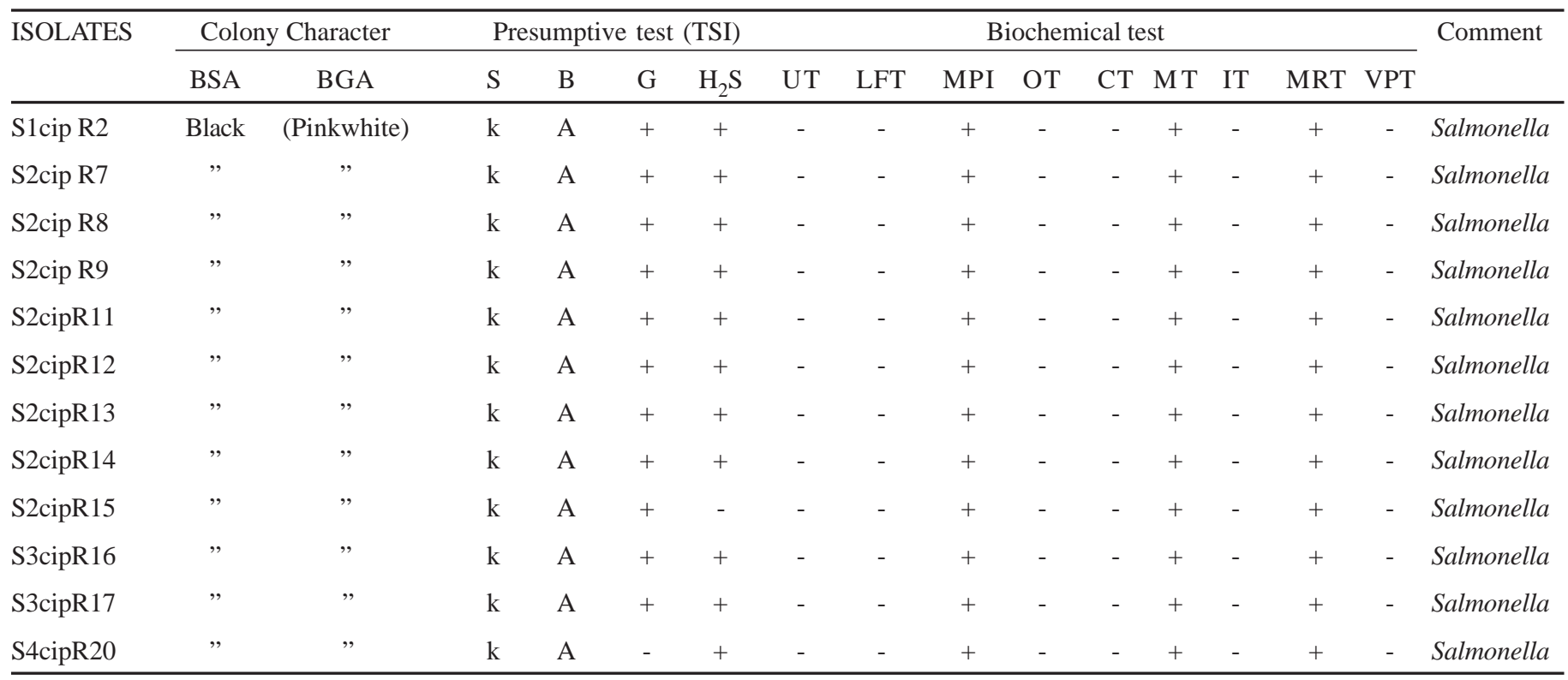

S:Slant, B:Butt, K:Alkaline,A:Acidic ,G:Gas 
Chowdhury et al.

Of 12 identified Salmonella, eight were isolated from sample 2. Two were isolated from sample 3. One was isolated from sample 1 and one was isolated from sample 4. Occurrence of ciprofloxacin resistant Salmonella in sample 1 indicated that ciprofloxacin resistant Salmonella was present in patient's discharges (Urine, Stool etc.). It was clear that more Salmonella were isolated from sample 2 (septic tank). After consumption, undigested portion of ciprofloxacin was entered into septic tank with patient discharges (urine, stool etc.) So, the microbes available in the septic tank became resistant. From sample 3 (outside drain through which septic tank wastes release into the environment), two ciprofloxacin resistant Salmonella were isolated that means from septic tank ciprofloxacin resistant Salmonella along with other resistant microbes occur in the sample 3 position. From sample 4(drain in front of hospital), one ciprofloxacin resistant Salmonella was isolated. Sample 4 had no direct connection with sample 1 and 2 but there were connection with sample 3, Chittagong Medical College student laboratory and pathological centre. From these sources residual antibiotic resistance may occur in the Sample 4. The occurrence of ciprofloxacin resistant Salmonella from sample 1, 2 and 3 indicated that ciprofloxacin resistance spread in and around Chittagong Medical College, that might be a serious environmental hazard, because from sample 3 (collected from drain by which hospital wastes distributed into different drain) these resistant Salmonella may spread to different drain in the surrounding environment.

Antibiotic bio-assay of ciprofloxacin resistant Salmonella showed that all 12 Salmonella isolates were multidrug resistant. From 12 resistant Salmonella, 11 were resistant to ampicillin. amoxicillin, penicillin and sensitive to tetracycline and chloramphenicol. One isolate (S1cipR20) was resistant to ampicillin, amoxicillin, penicillin, tetracycline and sensitive to chloramphenicol (Table 2).

Table 2. Antibiotic sensitivity test of ciprofloxacin resistant Salmonella isolates against several commercial antibiotic discs (Hi-media).

\begin{tabular}{lccccccc}
\hline Strain & \multicolumn{5}{c}{ Antibiotic sensitivity Zone diameter (mm) } & Resistance \\
\cline { 2 - 6 } & Cipro & Pen G & Amp & Amox & Tetracyc & Chloram & \\
\hline S1cipR2 & 0 & 0 & 0 & 0 & 22 & 25 & MDR \\
S2cipR7 & 0 & 0 & 0 & 0 & 23 & 25 & MDR \\
S2cipR8 & 0 & 0 & 0 & 0 & 18 & 20 & MDR \\
S2cipR9 & 0 & 0 & 0 & 0 & 20 & 22 & MDR \\
S2cipR11 & 0 & 0 & 0 & 0 & 15 & 20 & MDR \\
S2cipR12 & 0 & 0 & 8 & 8 & 18 & 20 & MDR \\
S2cipR13 & 0 & 0 & 0 & 0 & 16 & 20 & MDR \\
S2cipR14 & 0 & 0 & 0 & 0 & 12 & 15 & MDR \\
S2cipR15 & 0 & 6 & 7 & 8 & 18 & 18 & MDR \\
S3cipR16 & 0 & 0 & 0 & 0 & 16 & 20 & MDR \\
S3cipR17 & 0 & 0 & 0 & 0 & 15 & 21 & MDR \\
S4cipR20 & 0 & 0 & 0 & 0 & 0 & 15 & MDR \\
\hline
\end{tabular}

MDR: Multi Drug Resistant
Multidrug resistance in Solmonella is not uncommon; Therfall et al. ${ }^{18}$ reported multidrug resistant Salmonella from human and food animals in England and Wales. In this study, it was observed that, of 12 Salmonella isolates all were resistant to ciprofloxacin, amoxicillin, ampicillin, penicillin and these four antibiotics were most commonly recommend in Chittagong Medical College hospital that indicated unabsorbed portion of these antibiotics through patient discharges (urine, stool, etc.) play major role in the emergence of multiple drug resistance of these Salmonella isolates. The isolates were sensitive to chloramphenicol and tetracycline indicating that these two antibiotics may be good choice of treating Salmonella infection. Chloramphenicol is still proved as a low cost good sensitive antibiotic against Salmonella infection $^{1}$.

Growth measurement of four Salmonella from sample 1, 2, 3 and 4 at different concentrations of ciprofloxacin were done. In these experiment Salmonella isolated from sample 1, 2, 3 were found to grow against ciprofloxacin up to $500 \mu \mathrm{g} / \mathrm{ml}$ of growth media.

Table 3. Growth of Salmonella isolates at different concentrations of ciprofloxacin

\begin{tabular}{ccccc}
\hline Cipro conc & \multicolumn{4}{c}{ Growth of Salmonella isolates (OD at 600 nm) } \\
\cline { 2 - 5 }$(\mathrm{ig} / \mathrm{ml})$ & S1cipR2 & S2cipR7 & S3cipR16 & S4cipR20 \\
\hline 50 & 0.3 & 0.4 & 0.375 & 0.225 \\
100 & 0.275 & 0.377 & 0.353 & 0.175 \\
200 & 0.257 & 0.343 & 0.316 & 0.095 \\
300 & 0.190 & 0.311 & 0.296 & 0.015 \\
400 & 0.14 & 0.277 & 0.263 & - \\
500 & 0.1 & 0.252 & 0.241 & - \\
\hline
\end{tabular}

Salmonella isolated from sample 4 showed growth against ciprofloxacin up to $300 \mu \mathrm{g} / \mathrm{ml}$ of growth media (Table-3). This high resistance to ciprofloxacin by isolates from sample 1, 2, 3 may be the result of continuous release of undigested ciprofloxacin from patients. The emergence of antibiotic resistant bacteria in hospital wastes may be due to their flourish in the patient's intestines, or increasing use or misuse of the particular antibiotics against which the resistance developed were reported by many groups ${ }^{19-21}$. Our results are in concurrent with the above mention reports.

Plasmids were not found in the resistant Salmonella isolates. Cohen et al. reported that a multidrug resistance regulatory chromosomal locus is wide spread among enteric baeteria ${ }^{22}$. Nakaya et al. ${ }^{23}$ reported life threatening infantile diarrhea from Fluoroquinolone-resistant Salmonella enterica Typhimurium with mutation in both gyrA and porC. So the antibiotic resistance that observed in this study can be thought to be chromosomal gene or mutation mediated, but not plasmid mediated and the alarming thing is that in Chittagong bacterial antibiotic resistance are developing due to residual antibiotic contamination. 


\section{Conclusion}

The occurrences of ciprofloxacin resistance Salmonella in the hospital wastes is really an alarming factor for public health. This study revealed that different types of antibiotics are used in hospitals for treating diseases. After application, those antibiotics may be excreted by the patient or raw antibiotics can be found in the wastes as hospital discharges. These wastes are discharged in the environment from the hospitals. These can develop resistant microflora against those antibiotics in the environment. That is why all the isolated ciprofloxacin resistant Salmonella showed resistance to common antibiotics used in $\mathrm{CMCH}$. The presence of multidrug resistant pathogen in hospital wastes may contribute to develop potential problem in public health. This study in some extent favours the necessity of taking immediate step to solve this problem.

\section{References}

1. Chakraborty P. 1995. In: A Text Book of Microbiology ,1 $1^{\text {st }}$ edn.,p.149150. New Central Book Agency (P) Ltd.

2. Crump JA, Lubsy SP \& Mintz ED. 2004. The global burden of enteric fever. Bull. W. H. O. 82:346-353. Dashti AA, Jadaon MM, Habeeb F, West PW, Panigrahi D \& Amyes GBS.2008. Salmonella enterica serotype Typhi in Kuwait and its reduced susceptibility to ciprofloxacin. J Chemother. 20:38-43

3. Bhal R and Bhatnagar S. 2005. Typhoid and paratyphoid fever. Lancet 366:749-762.

4. Brown JC, Shanahan PMA, Jesudason MV, Thomson CJ and Amyes SGB. 1996. Mutations responsible for reduced susceptibility to 4quinolones in clinical isolates of multi-resistant Salmonella typhi in Indian J Antmcrob Chemo 37: 891-900.

5. Jesudason MV, Malathy B and John TJ. 1996. Trend of increasing minimum inhibitory concentration of ciprofloxacin to Salmonella typhi. Indian J Med Res. 103: 247-249.

6. Rahman MM, Haq JA, Morshed MA and Rahman MA. 2005. Salmonella enterica serovar Typhi with decreased susceptibility to ciprofloxacin-an emerging problem in Bangladesh. Int J Antimicrbo Agents. 25: 345-346.

7. Threlfall EJ and Ward LR. 2001. Decreased susceptibility to ciprofloxacin in Salmonella enterica serotype Typhi, United Kingdom. Emerg Infect Dis. 7: 448-450.

8. Wain J, Hoa NTT, Chinh NT, Vinh H, Everett MJ, Diep TS, Day NPJ, Solomon T, White NJ, Piddock LJ and Parry CM. 1997. Quinolone-resistant Salmonella typhi in VietNam: molecular basis of resistance and clinical response to treatment. Clin Infect Dis. 25: 1404-1410.

9. Dimitrov T, Udo EE, Albaksami O, Kilani AA and Shehab EMR. 2007. Ciprofloxacin treatment failure in a case of typhoid fever caused by Salmonella enterica serotype Paratyphi A with reduced susceptibility to ciprofloxacin. J Med Microbiol. 56: 277-279.
10. Dashti AA, Jadaon MM, Habeeb F, West PW, Panigrahi D and Amyes GBS.2008. Salmonella enterica serotype Typhi in Kuwait and its reduced susceptibility to ciprofloxacin. J Chemother. 20: 38-43

11. Gaind R, Paglietti B, Murgia M, Dawar R, Uzzau S, Cappuccinelli P, Deb M, Aggarwal P and Rubino S. 2006. Molecular characterization of ciprofloxacin-resistant Salmonella enterica serovar Typhi and Paratyphi A causing enteric fever in India. J Antimicrob Chemother. 58:1139-1144.

12. Renuka K, Sood S, Das BK and Kapil A. 2005. High-level ciprofloxacin resistance in Salmonella enterica serotype Typhi in India. J Med Microbiol. 54: 999-1000.

13. Ahmed D, D’Costa LT, Alam K, Nair GB and Hossain MA. 2006. Multi-resistant Salmonella enterica serovar Typhi isolates with highlevel resistance to ciprofloxacin in Dhaka, Bangladesh. Antimicrob Agents Chemother. 50: 3516-3517.

14. Saha SK, Darmstadt GL, Baqui AH, Crook DW, Islam MN, Hossain M, Arifeen SE, Santosham M and Black RE. 2006. Molecular basis of resistance displayed by highly ciprofloxacin-resistant Salmonella enterica serovar Typhi in Bangladesh. J Clin Microbiol. 44:38113813.

15. Chau TT, Campbell JI, Galindo CM, Hoang NVM, Diep TS and Dolecek C. 2007. Antimicrobial drug resistance of Salmonella enterica serovar Typhi in Asia and molecular mechanism of reduced susceptibility to the fluoroquinolones. Antimicrob Agents Chemother. 51:4315-4323.

16. Bauer AW, Kirby WM, Sherris JC and Turek M. 1966. Antibiotic susceptibility testing by standard single disc method. Amer J Clin Pathol. 45 (4):496.

17. Sambrook J, Fritsch EF and Maniatis T. 1989. Molecular Cloning: a laboratory manual. $2^{\text {nd }}$ edn. Cold Spring Harbor Laboratory Press, Cold Spring Harbor, New York, USA.

18. Threlfall EJ, Ward LR and Rowe B. 1993. A comparison of multiple drug resistance in Salmonella from human and Food animals in England and Wales, 1981 and 1990. Epidemiol Infect. 111: 189-97.

19 Bhan MK, Blondeau JM and Yaschuk Y. 1996. Canadian ciprofloxacin susceptibility study. Comparative study from 15 medical centers. Antimicrob Agents Chemother. 40:1729-32.

20. Acar JF and Goldstein FW.1997. Trends in bacterial resistance to fluoroquinolones. Clin Infect Dis. 24:67-73

21. Richard P, Delangle MH, Merrien D, Barille S, Reynaud A and Minozzi C. 1994. Fluoroquinolone use and fluoroquinolone resistance: Is there an association? Clin Infect Dis. 19:54-59.

22. Cohen SP, Yan W and Levy SB. 1993. A multidrug resistance regulatory chromosomal locus is widespread among enteric bacteria. J Inf Dis. 168: 484-488.

23. Nakaya H, Yasuhara A, Youshimura K, Oshiloi Y, Izumiya H and Watanabe H. 2003. Life-threatening infantile diarrhea from fluoroquinolone-resistant Salmonella enterica Typhimurium with mutations in both gyrA and parC. Energ Infect Dis. Available from internet at: URL: http://www.cdc.gov/ncidod/EID/vol9no2/020185.htm. 